\title{
KEPERCAYAAN DAN PRAKTIK BUDAYA PADA MASA KEHAMILAN MASYARAKAT DESA KARANGSARI, KABUPATEN GARUT
}

\author{
Juariah \\ Badan Penelitian dan Pengembangan Daerah Provinsi Jawa Barat \\ E-mail: ai_arriandhi@yahoo.co.id
}

\begin{abstract}
ABSTRAK. Desa Karangsari Kabupaten Garut telah mengalami perubahan secara fisik karena adanya beberapa tempat wisata, sehingga perlu dilakukan kajian mengenai praktik-praktik budaya pada masa kehamilan di daerah tersebut, termasuk apakah masyarakat masih mempertahankan budaya yang dianut selama ini, ataukah sudah terjadi pergeseran nilai budaya sebagai pengaruh dari perubahan fisik yang terjadi. Penelitian ini bertujuan untuk mengeksplorasi kepercayaan dan praktik budaya masyarakat Desa Karangsari pada masa kehamilan, serta manfaat dan dampak dari praktik tersebut terhadap kesehatan ibu dan janinnya. Penelitian ini menggunakan metode penelitian deskriptif analisis, melalui pendekatan studi kasus, dengan informan berjumlah 20 orang. Data hasil wawancara dianalisis dengan analisis isi. Hasil penelitian ini menunjukkan bahwa masyarakat Desa Karangsari masih mengikuti kebiasaan yang harus dilakukan ibu pada saat hamil dan juga pantangan/larangan yang harus dihindari oleh ibu hamil, dengan keyakinan jika pantangan itu dilanggar akan mengakibatkan hal buruk pada ibu dan bayi yang dikandungnya. Masyarakat Desa Karangsari juga masih mempertahankan adat upacara opat bulanan dan nujuh bulanan walaupun dalam pelaksanaannya disesuaikan dengan kemampuan ibu hamil dan keluarganya. Suami terlibat dalam kehamilan istrinya dengan mengikuti keharusan dan pantangan dan meyakini akan ada akibat buruk jika tidak mengikuti kebiasaan tersebut. Tenaga kesehatan dan maraji pemanfaatannya saling berdampingan, walaupun maraji memiliki otoritas terutama dalam ritual seremonial.
\end{abstract}

Kata kunci: Kepercayaan, Praktik, Budaya Masa Kehamilan

\section{CULTURAL PRACTICES AND BELIEFS DURING PREGNANCY OF KARANGSARI VILLAGE COMMUNITY, GARUT DISTRICT}

\begin{abstract}
Karangsari Village, Garut has undergone physical changes due to several tourist destination. Therefore, it is need to be done a study on cultural practices during pregnancy, including whether people still maintain the culture or has been a shift in cultural values as the effect of physical changes that is happened. Purpose of this study was to explore cultural practices and beliefs of Karangsari Village community during pregnancy and the benefit and impact of such practices on the health of the mothers and their baby. This study used a case study method. Number of informants was 20 people. Data from interviews were analyzed by content analysis. Results of this study indicated that the villagers still followed the customs and restrictions/taboos during pregnancy. They believed that if it was contravened will lead to bad things for mother and her baby. They also still retained opat bulanan and nujuh bulanan, although it was adjusted with the ability of pregnant women and their families. Involvement husbands obeyed rituals and taboos and they believed there would be bad consequences if not followed these traditions. Maraji and health care professionals complemented each other, even maraji had authority in leading ritual ceremonies.
\end{abstract}

Key words: Beliefs, Practices, Cultural During Pregnancy

\section{PENDAHULUAN}

Kehamilan dan persalinan merupakan fase krisis dalam kehidupan seorang wanita. Peristiwa ini memiliki dampak pada bagaimana seorang wanita melewati fase transisi untuk menjadi ibu termasuk kesehatan fisik dan mentalnya dan juga kesejahteraan keluarga secara keseluruhan (Beech and Phipps, 2004: 61). Van Gennep (1960) dalam Winson (2006) menggambarkan status sosial seorang wanita pada saat hamil berada pada status marginality di mana dia mulai berperilaku berbeda dari biasanya misalnya dengan memperhatikan pola makan, aktifitas, dan lain-lain.

Masyarakat di berbagai budaya memberi perhatian pada fase krisis ini. Pada masa kehamilan ada banyak ritual yang harus dilakukan yang menandakan bahwa masyarakat di budaya mana pun menganggap kehamilan sebagai peristiwa yang luar biasa, bukan hanya dalam kehidupan wanita hamil itu sendiri tetapi juga suami dan keluarganya. Perhatian masyarakat terhadap ibu yang sedang hamil merupakan bentuk dukungan sosial. Menurut McCourt (2006) ada tiga komponen kunci dukungan sosial yaitu dukungan emosional, dukungan informasi dan dukungan praktis. Dukungan emosional ditunjukkan dengan hubungan yang hangat, persaudaraan, persahabatan dan keinginan untuk mendengar. Saran dan informasi yang baik merupakan contoh dari dukungan informasi. Sedangkan dukungan finansial pada ibu hamil, pijat untuk mengurangi ketidaknyamanan merupakan bentuk nyata dukungan praktis.

Dukungan sosial selama kehamilan sangat penting untuk mengurangi stress. Selama kehamilan dukungan dapat menimbulkan rasa percaya diri pada wanita bahwa dia memiliki persiapan yang cukup untuk melahirkan. Menurut Oakley (1990) dalam Mander (2001) dukungan sosial berperan positif pada kesehatan, secara tidak langsung mengurangi bahaya yang disebabkan stress, mengurangi resiko terpapar stress dan memudahkan penyembuhan dari kondisi stress seperti sakit. 
Bukan hanya calon ibu, calon ayah pun berada pada periode transisi atau marginalitas (Van Gennep, 1960) dalam Blackshaw (2003). Hal ini karena meskipun kehamilan dan persalinan merupakan peristiwa yang dialami perempuan, secara fisik dan sosial, laki-laki terlibat secara mendalam pada kelahiran anak-anaknya. Pada berbagai budaya calon ayah memiliki peranan untuk melakukan ritual tertentu selama periode kehamilan. Tugas-tugas itu dilakukan untuk melindungi ibu dan anaknya serta untuk mempermudah proses persalinan. Heggenhougan (1980) dalam Helman (2002) menyebutnya sebagai ritual couvade (couvade berasal dari bahasa Perancis, Basque yang artinya mengerami) yang mana ayah diminta untuk mengikuti tabu atau pantangan tertentu. Menurut Heggenhougan ritual couvade merupakan suatu keterlibatan yang disadari atau mungkin tidak disadari. Seorang calon ayah akan melakukan berbagai ritual selama kehamilan seperti perilaku, diet, spiritual dan sexual, fenomena psikosomatik, pendidikan menjadi orangtua serta menghindari hal-hal yang bersifat polutan.

Budaya pada masa kehamilan dan persalinan di sebagian daerah telah terjadi pergeseran namun di sebagian lain masih dipertahankan. Hal ini seperti yang dijelaskan oleh O’Neil (2006) bahwa semua budaya yang diwariskan cenderung untuk berubah tetapi ada kalanya juga dipertahankan. Ada proses dinamis yang mendukung diterimanya hal-hal dan ide-ide baru dan ada juga yang mendukung untuk mempertahankan kestabilan budaya yang ada. Hiller (2003) menyatakan bahwa ketika perubahan terjadi, maka terjadi destruksi nilainilai tradisional, kepercayaan, peran dan tanggungjawab, pendidikan, keluarga dan lain-lain yang hampir simultan dengan proses konstruksi cara baru sebagai pengaruh dari perubahan sosial. Nilai dan ritual yang baru ini menggantikan nilai dan ritual yang lama. Namun di sebagian masyarakat adakalanya terjadi kompromi yang mana nilai dan ritual baru dijalankan dengan tanpa menghilangkan nilai dan ritual lama.

Desa Karangsari yang termasuk wilayah Kecamatan Pakenjeng Kabupaten Garut berada di pesisir Jawa Barat Selatan. Desa ini telah mengalami perubahan secara fisik karena berdekatan dengan beberapa pantai yang sekarang menjadi tempat wisata yaitu pantai Sayang Heulang, Santolo dan Rancabuaya. Masyarakat di Desa ini, memiliki adat istiadat yang kuat mengenai kesehatan ibu dan anak termasuk budaya pada masa kehamilan. Sampai saat ini belum banyak diungkap mengenai praktik-praktik budaya pada masa kehamilan di daerah tersebut termasuk apakah masyarakat masih mempertahankan budaya yang dianut selama ini ataukah sudah terjadi pergeseran nilai budaya sebagai pengaruh dari perubahan fisik yang terjadi. Oleh karena itu penelitian ini bertujuan untuk mengeksplorasi kepercayaan dan praktik budaya masyarakat Desa Karangsari pada masa kehamilan yang meliputi kebiasaan yang harus dilakukan ibu pada saat hamil, pantangan/larangan yang harus diikuti ibu pada saat hamil, upacara pada masa kehamilan serta ritual yang dilakukan suami pada saat istrinya sedang hamil. Selain itu juga untuk mendapatkan penjelasan dari masyarakat mengenai manfaat dan dampak dari praktik tersebut terhadap kesehatan ibu dan janinnya.

\section{METODE}

Penelitian ini menggunakan metode penelitian deskriptif analisis, melalui kajian studi kasus untuk mengeksplorasi kepercayaan dan praktik budaya pada masa kehamilan. Penelitian dilaksanakan pada bulan Januari 2016 bertempat di Desa Karangsari Kecamatan Pakenjeng Kabupaten Garut. Sumber data penelitian ini adalah kata-kata informan. Jumlah informan penelitian ini ada 20 orang yang terdiri dari dua orang maraji (dukun bersalin), satu orang tetua kampung, dua orang kader, sebelas orang ibu hamil dan lima orang ibu menyusui.

Jenis data dalam penelitian ini adalah data primer dan data sekunder. Data primer didapatkan dari hasil wawancara dengan informan sedangkan data sekunder merupakan hasil telaah dokumen. Pengumpulan data dilakukan dengan wawancara dan menelaah dokumen yang ada yaitu profil desa. Instrumen yang digunakan dalam penelitian ini adalah peneliti sendiri dan pedoman wawancara. Pada waktu melakukan wawancara dibantu dengan alat perekam suara. Pengolahan dan analisis data menggunakan tahapan transkripsi data, pengorganisasian data, pengenalan dan koding. Data yang sudah diolah dianalisis dengan menggunakan analisis isi (content analysis) dan disajikan dalam bentuk narasi dan tabel. Data hasil penelitian diinterpretasikan untuk memperoleh makna yang luas dan mendalam. Hasil penelitian dibahas dengan cara membandingkan hasil penelitian dengan teori yang relevan.

\section{HASIL DAN PEMBAHASAN}

\section{Gambaran Umum Desa Karangsari}

Desa Karangsari termasuk wilayah Kecamatan Pakenjeng Kabupaten Garut. Jarak dengan ibu kota kecamatan sekitar 12 kilometer dan jarak dengan Ibu kota kabupaten sekitar 75 kilometer. Desa ini memiliki luas wilayah 1.642 hektar yang terbagi atas empat kampung yaitu Mekarlaksana, Cicalengka, Parabon dan Cidahon. Jumlah penduduk Desa Karangsari ada 5.793 jiwa terdiri dari 2.874 jiwa penduduk laki-laki dan 2.919 jiwa penduduk perempuan. Tingkat pendidikan penduduk $50 \%$ tamat SD dan 32\% berpendidikan SMP. Hal ini kemungkinan disebabkan karena akses masyarakat untuk melanjutkan ke sekolah SMA belum tersedia di Desa Karangsari bahkan di kecamatan Pakenjeng.

Fasilitas kesehatan yang ada di Desa Karangsari hanya ada satu puskesmas pembantu yang buka dua kali dalam seminggu. Sedangkan tenaga kesehatan yang ada 
di desa ini adalah satu orang bidan desa dan satu orang mantri (perawat) yang sudah tinggal menetap selama puluhan tahun. Selain itu di desa ini masih ada dua orang maraji yang masih dipercaya masyarakat untuk membantu dalam urusan kesehatan ibu dan anak. Pada praktiknya, maraji berdampingan dan saling melengkapi dengan bidan dan mantri.

\section{Kepercayaan Dan Praktik Budaya Pada Masa Kehamilan}

Kebiasaan Yang Dilakukan Ibu Pada Saat Hamil

Berdasarkan hasil wawancara kebiasaan-kebiasaan yang masih dipatuhi ibu pada saat hamil di Desa Karangsari dapat dilihat pada tabel berikut ini.

Tabel 1. Kebiasaan yang Dilakukan Ibu Pada Saat Hamil

\begin{tabular}{|c|c|c|}
\hline No & Kebiasaan & Pengaruh yang diyakini \\
\hline 1 & $\begin{array}{l}\text { Membawa benda-benda tajam } \\
\text { seperti gunting, peniti yang } \\
\text { diikatkan pada baju atau } \\
\text { pakaian dalam ibu hamil }\end{array}$ & $\begin{array}{l}\text { menjaga ibu dan bayinya } \\
\text { dari gangguan roh jahat } \\
\text { dan makhluk halus }\end{array}$ \\
\hline 2 & $\begin{array}{l}\text { Banyak bergerak dan jalan- } \\
\text { jalan terutama pada pagi hari } \\
\text { saat udara masih segar }\end{array}$ & $\begin{array}{l}\text { supaya persalinannya } \\
\text { lancar }\end{array}$ \\
\hline 3 & $\begin{array}{l}\text { Ibu yang hamil tua, dianjurkan } \\
\text { untuk sering melakukan } \\
\text { gerakan menungging termasuk } \\
\text { mengepel lantai dengan } \\
\text { menggunakan tangan }\end{array}$ & $\begin{array}{l}\text { supaya janin yang di dalam } \\
\text { kandungan cepat turun dan } \\
\text { membuka jalan lahir serta } \\
\text { membuat persalinan lancar } \\
\text { tanpa kesulitan. }\end{array}$ \\
\hline 4 & $\begin{array}{l}\text { Ibu hamil yang berambut } \\
\text { panjang dianjurkan untuk } \\
\text { mengikat rambutnya }\end{array}$ & $\begin{array}{l}\text { supaya kelihatan rapi dan } \\
\text { bersih }\end{array}$ \\
\hline 5 & $\begin{array}{l}\text { Dianjurkan untuk makan lebih } \\
\text { banyak dan lebih sering, banyak } \\
\text { mengkonsumsi sayuran, buah- } \\
\text { buahan, susu dan makanan bergizi }\end{array}$ & $\begin{array}{l}\text { supaya ibu dan bayi yang } \\
\text { dikandungnya sehat }\end{array}$ \\
\hline 6 & $\begin{array}{l}\text { Dianjurkan untuk makan daun } \\
\text { galing yaitu tumbuhan sejenis pakis } \\
\text { yang mengandung banyak lendir }\end{array}$ & $\begin{array}{l}\text { Memperlancar } \\
\text { proses persalinan }\end{array}$ \\
\hline 7 & $\begin{array}{l}\text { Dipijat (bahasa } \\
\text { sunda:'disangsurkeun') }\end{array}$ & $\begin{array}{l}\text { Supaya bayi tidak turun ke } \\
\text { bawah dan posisi bayi tidak } \\
\text { berubah }\end{array}$ \\
\hline
\end{tabular}

Sumber: Data Primer

Budaya di masyarakat memiliki resep tentang makanan atau minuman yang tepat untuk memperlancar proses fisiologis kehamilan (Helman:2002) yang dipercaya akan berdampak terhadap kelancaran persalinan dan pasca salin. Anjuran makanan pada ibu hamil di Desa Karangsari sejalan dengan hasil penelitian M'soka et al (2010) di Zambia yang mana ibu hamil meyakini perlunya diet seimbang.

Hasil studi Higginbottom (2014) di Canada juga menemukan wanita hamil harus makan lebih sering dan atau dengan porsi yang lebih besar, banyak minum susu (dan juga jus apel) supaya kulit bayinya bagus dan juga untuk kesehatan dan kesejahteraan janin. Selain itu, penelitian yang dilakukan Otoo (2015) di Ghana menemukan buah-buahan, kepiting dan pisang mentah baik untuk ibu hamil karena buah-buahan dan kepiting membuat ibu dan janin sehat dan pisang mentah keras sehingga membuat janin kuat dan juga memberi kekuatan pada ibu saat persalinan.

Studi Graft (2014) yang melakukan studi ke wanita dari 35 etnik yang ada di Ghana tentang keyakinan dan praktik makanan dalam kehamilan menyimpulkan bahwa makanan tradisional dan suplemen memiliki lima fungsi yaitu mencegah anemia, menguatkan tubuh ibu hamil, meningkatkan kesehatan, meminimalkan gangguan fisiologis dan memaksimalkan kesehatan bayi.

Perilaku atau kebiasaan saat hamil juga harus dijaga sebagai bentuk perlindungan terhadap ibu dan janin. Keharusan menjaga perilaku dan menghindari pertengkaran ditekankan pada ibu hamil (Naidu:2013; M'soka et al: 2010). Wanita hamil juga hanya makan yang dimasak sendiri atau keluarganya, menggunakan artefak religi dan membawa kitab suci (Aziato et al:2016).

\section{Pantangan/Larangan Yang Harus Diikuti Ibu Pada Saat Hamil}

Berdasarkan hasil wawancara mengenai pantanganpantangan yang harus diikuti ibu pada saat hamil di Desa Karangsari dapat dilihat pada tabel Tabel 2.

Pantangan makanan selama kehamilan di masyarakat Karangsari sejalan dengan hasil penelitian Otoo (2015) di Ghana tentang larangan makan siput, pisang matang, okra, kacang tanah, milo, gandum, kentang, jahe dan mangga. Selain itu juga pembatasan makanan tertentu seperti gula tebu, alkohol, garam (M'soka et al: 2010). Masyarakat Ankara, Turki ada larangan makan ikan, kepala dan kaki domba serta daging kelinci (Ayaz \& Efe: 2008).

Keharusan untuk memperhatikan perilaku atau aktifitas pada ibu hamil di Desa Karangsari juga ditemukan di berbagai daerah, seperti di Ghana ibu hamil tidak boleh menyiapkan atau mendekati api, dilarang melilitkan handuk atau kain di leher, memperlihatkan dada, membawa atau memikul barang-barang berat (Otoo: 2015). Selain itu, Ibu hamil di Desa Karangsari juga dilarang keluar dan jalan-jalan di malam hari karena khawatir diganggu oleh roh jahat. Secara fisik, penerangan di Desa Karangsari pada malam hari memang masih kurang sehingga khawatir ibu terjatuh, terlebih pada musim hujan, jalanan banyak yang licin. Selain itu karena lokasinya yang dekat dengan pantai wisata, di Desa Karangsari juga masih ada preman yang berkeliaran di malam hari sehingga akan sangat berbahaya bagi ibu hamil.

\section{Syukuran atau Upacara Pada Masa Kehamilan}

Hasil wawancara dengan informan mengenai upacara yang biasa dilakukan pada masa kehamilan didapatkan bahwa di Desa Karangsari masyarakat masih mempertahankan kebiasaan upacara opat bulanan dan nujuh bulanan. Upacara opat bulanan dilaksanakan pada saat usia kehamilan ibu menginjak empat bulan karena diyakini pada usia ini ditiupkan ruh ke dalam janin. Syukuran ini mengundang keluarga dan tetangga terdekat. 
Tabel 2. Pantangan/Larangan Yang Harus Diikuti Ibu Pada Saat Hamil

\begin{tabular}{|c|c|c|}
\hline No & Larangan/Pantangan & Akibat yang diyakini \\
\hline 1 & Memakai pakaian yang sobek & bayinya akan cacat \\
\hline 2 & Keluar dan jalan-jalan di malam hari & akan diikuti dan diganggu oleh roh-roh halus \\
\hline 3 & Duduk di bangbarung (depan pintu) & susah pada saat melahirkan \\
\hline 4 & $\begin{array}{l}\text { Duduk di teras rumah dengan kaki ngarumbay (berselonjor ke } \\
\text { tanah) }\end{array}$ & menghambat kelahiran sang bayi \\
\hline 5 & Duduk di atas batu & menghambat kelahiran sang bayi \\
\hline 6 & Duduk di sembarang tempat & menghambat kelahiran sang bayi \\
\hline 7 & Melilitkan handuk di leher & tali pusat/ari-arinya melilit \\
\hline 8 & Melihat orang yang sedang membolongi sesuatu & ada bekas bolongan di telinga anak \\
\hline 9 & Makan es & menyebabkan besar saat bayi dan lama-lama menjadi kecil \\
\hline 10 & Makan bakso & menyebabkan bayi besar \\
\hline 11 & Makan jengkol & bayi yang lahir akan bau \\
\hline 12 & Makan nenas & menyebabkan keguguran \\
\hline 13 & Makan ikan asin & mengakibatkan gatal pada ibu \\
\hline 14 & Makan ikan tongkol dan sarden & mengakibatkan perdarahan \\
\hline 15 & Makan pisang & mengakibatkan rahimnya keluar \\
\hline 16 & Makan mie & mengakibatkan rahimnya keluar \\
\hline 17 & Makan nangka & mengakibatkan rahimnya keluar \\
\hline 18 & Memakan buah-buahan yang menyatu/berdempet & Mengakibatkan bayi yang akan dilahirkan kembar siam. \\
\hline
\end{tabular}

Sumber: Data Primer

Besar kecilnya acara syukuran ini disesuaikan dengan kemampuan ibu hamil dan keluarganya. Tetapi ada beberapa persyaratan yang harus ada yaitu empat macam buah-buahan yang dibuat rujak dan empat macam 'beubeutian' (umbi-umbian) yang 'diseupan' (dikukus). Kemudian Ibu hamil harus menjual rujak itu kepada keluarga dan tetangga yang hadir, dan mereka membelinya dengan potongan genting yang berbentuk bulat seperti koin (uang recehan). Semakin banyak yang membeli maka diyakini proses kehamilan dan persalinan ibu akan semakin dimudahkan.

Pada upacara ini ibu hamil juga dimandikan oleh orang tua dan keluarganya dengan air yang dicampur dengan empat jenis bunga-bungaan yang sudah dijampijampi oleh maraji. Selain itu juga diadakan pengajian dan pada proses pengajian ini dibacakan Surah Yaasin, Surah Yusuf dan Surah An-Nisaa. Pengajian ini bertujuan untuk mendo'akan supaya persalinan lancar dan anak yang dilahirkan sehat, sholeh dan ganteng jika laki-laki serta sholehah dan cantik jika perempuan.

Upacara ini sebagai ungkapan rasa syukur karena sudah diberi kepercayaan untuk hamil, mengakrabkan anggota keluarga dan tetangga dan sama-sama memberikan dukungan kepada ibu hamil dan suaminya.

Di usia kehamilan tujuh bulan, diadakan upacara yang serupa. Bedanya pada usia kehamilan ini buahbuahan yang disediakan untuk dibuat rujak, 'beubeutian' (umbi-umbian) yang 'diseupan' (dikukus), dan bungabungaan yang dicampur dengan air pada saat mandi, masing-masing jumlahnya ada tujuh macam.

Prosesi upacara ini sama dengan upacara opat bulanan yaitu ibu hamil menjual rujak kepada keluarga dan tetangga yang datang, dan mereka membeli dengan menggunakan genting yang dibentuk seperti koin. Ibu dimandikan dengan air yang dicampur tujuh macam bunga oleh orangtua dan keluarganya dengan dipimpin oleh maraji. Selain itu juga dilaksanakan kegiatan pengajian yang dipimpin oleh Ustadz dan diikuti oleh keluarga dan tetangga yang tujuannya untuk mendo'akan agar ibu sehat dan selamat serta bayi yang dikandungnya sehat, selamat, cantik/cakep dan pintar sesuai harapan orangtuanya.

Upacara opat bulanan dan nujuh bulanan ini meskipun bagian dari budaya masyarakat Karangsari secara turun-temurun, namun dalam pelaksanaannya tidak memaksa, jadi sesuai dengan kemampuan ibu hamil dan keluarganya. Besar kecilnya penyelenggaraan upacara tidak dinilai oleh masyarakat, yang penting upacara ini dilaksanakan. Kepatuhan terhadap tradisi ini juga terjadi pada masyarakat Buton yang masih mempertahankan upacara posipo (upacara untuk ibu hamil anak pertama) (Hindaryatiningsih: 2016).

Upacara opat bulanan dan nujuh bulanan yang masih menjadi ritual yang dipatuhi oleh masyarakat Desa Karangsari memiliki makna yang sangat dalam. Ritual inisiasi menyampaikan pesan simbolis yang menyuarakan nilai dan keyakinan budaya yang sangat dalam (DavisFloyd: 1992) dan bertujuan untuk melindungi ibu dan janin (dan kadang juga ayah, kerabat dan seluruh keluarga) dari kekuatan jahat (Van Gennep: 2004). Upacara seperti ini juga merupakan bentuk perhatian keluarga dan tetangga serta masyarakat sekitar (Badan Penelitian dan Pengembangan Kesehatan Kementerian Kesehatan RI: 2012) dan juga bertujuan untuk mengenalkan nilai-nilai kebaikan seperti nilai kebersamaan, nilai respect, nilai sosial yang diwujudkan dalam kerelaan membagikan rizki kepada sanak keluarga dan handai taulan yang hadir, sejak anak di dalam kandungan (Hindaryatiningsih: 2016).

Rowan (2006) menjelaskan bahwa hubungan antara ibu dan bayinya dimulai saat kehamilan dan perhatian calon ibu meningkat saat bayi mulai bergerak. 
Perasaan ibu tentang bayinya akan sangat tergantung pada dukungan yang dia dapatkan dari suami, kerabat dan orang sekitar. Dukungan sosial memiliki manfaat untuk mengurangi stress (Glazier et al: 2004, Thomas et al : 2015, Mirabzadeh et al dalam Maharlouei: 2016), mendukung pola makan yang baik dan perilaku yang sehat (Higginbottom: 2014) juga memberi kepuasan pada ibu hamil (Gebuza et al: 2016).

\section{Ritual Suami Dalam Kehamilan}

Hasil wawancara dengan informan, memperlihatkan bahwa kebiasaan-kebiasaan yang harus dilakukan suami pada saat istrinya sedang hamil di Desa Karangsari antara lain suami harus sering mengucapkan 'amit-amit' terutama jika melihat atau mendengar halhal yang tidak disukai atau tidak menyenangkan. Hal ini agar bayi terhindar dari yang tidak diinginkan. Selain itu, setiap matahari meredup atau datang waktu magrib, seorang suami harus mengunyah 'panglay' (bumbu dapur sejenis lengkuas) lalu dimuntahkan di setiap sudut rumah dan di depan pintu agar tidak ada yang mengganggu.

Masyarakat Karangsari meyakini bahwa jika ritual itu tidak dilakukan maka nyawa ibu dan bayinya akan terancam dan banyak sekali gangguan yang dapat terjadi pada ibu maupun bayinya. Masyarakat Karangsari juga meyakini bahwa ada pantangan-pantangan yang harus diikuti suami selama istrinya hamil.

Hasil wawancara mengungkap beberapa pantangan tersebut antara lain para calon ayah dilarang untuk menyembelih hewan seperti ayam, domba, ular dan sebagainya karena diyakini bayi yang dilahirkan nanti lehernya akan merah-merah. Calon ayah juga dilarang berbicara kasar/seenaknya, tujuannya untuk keselamatan ibu dan bayinya. Selain itu juga calon ayah dilarang melilitkan handuk ke leher karena dipercaya leher bayi akan terlilit tali pusat sehingga bayi akan sulit lahir pada saat persalinan. Selama istrinya hamil, suami juga dilarang memancing karena dipercaya bayi yang dikandung istrinya dapat mengalami cacat bibir sumbing.

Meskipun ada pantangan-pantangan tersebut, namun masyarakat Karangsari meyakini bahwa pantangan itu boleh dilakukan asal calon ayah mengajak bayi yang ada di dalam kandungan istrinya meskipun berjauhan misalnya calon ayah ada di Bandung sementara istrinya yang sedang hamil di Karangsari, pada saat dia akan melakukan satu kegiatan yang dilarang seperti memancing, dengan berkata "dede utun ayo mancing" (adik bayi ayo memancing). Dengan mengajak ini maka dipercaya bahwa akibat yang ditakutkan yaitu tali pusat melilit pada leher tidak akan terjadi pada bayinya.

Serangkaian ritual yang harus dilakukan oleh suami selama periode kehamilan, persalinan dan postpartum istrinya yang dikenal dengan Ritual couvade merupakan bentuk keterlibatan suami (Helman:2002, Cooper: 2005). Rasa empati suami pada istrinya seringkali muncul dalam bentuk couvade syndrome baik dalam bentuk gejala fisik maupun psikologis (Kazmierczak: 2013, Ganapathy: 2014)

Pada masyarakat tradisional, kehamilan dan persalinan merupakan proses yang normal dan sebagai identitas bagi seorang perempuan (Hillier: 2003). Untuk meyakinkan kesehatan dan keselamatan ibu dan bayinya, masyarakat Desa Karangsari memeriksakan kehamilannya ke bidan dan juga tetap memanfaatkan paraji untuk memeriksa kehamilan, memimpin ritual upacara opat bulanan dan nujuh bulanan dan juga memberikan saran-saran untuk keselamatan diri dan bayinya.

Hal yang dikemukakan di atas sejalan dengan hasil penelitian Agus et al (2012), Almutahar (2014) dan Choguya (2014) yang mana dukun bersalin memiliki otoritas dalam kehamilan dan persalinan. Dengan demikian, masyarakat Desa Karangsari memanfaatkan akses terhadap pelayanan kesehatan dengan tetap mempertahankan praktik-praktik tradisional yang didapatkan secara turun-temurun, sesuai dengan hasil kajian Otoo (2015) dan Choudhury et al (2012).

\section{SIMPULAN}

Masyarakat Desa Karangsari masih mengikuti kebiasaankebiasaan yang harus dilakukan ibu pada saat hamil dan juga pantangan/larangan yang harus dihindari oleh ibu hamil. Mereka meyakini jika pantangan itu dilanggar akan mengakibatkan hal buruk pada ibu dan bayi yang dikandungnya. Suami memiliki keterlibatan dengan kehamilan istrinya yang ditunjukkan dengan kepatuhan suami mengikuti keharusan dan pantangan dan keyakinan akan akibat jika kebiasaan tersebut tidak diikuti.

Adat upacara opat bulanan dan nujuh bulanan masih dipertahankan oleh masyarakat desa ini, walaupun dalam pelaksanaannya disesuaikan dengan kemampuan ibu hamil dan keluarganya. Maraji memiliki peran penting dalam memimpin upacara-upacara ini. Dengan demikian maraji masih memiliki otoritas dalam pelayanan kehamilan, walaupun pemanfaatannya oleh masyarakat berdampingan dan saling melengkapi dengan tenaga kesehatan.

\section{DAFTAR PUSTAKA}

Agus, Y., Horiuchi, S. and Porter. S. (2012). Rural Indonesia women's traditional beliefs about antenatal care. BMC Research, 5:589. http:// www.biomedcentral.com/1756-0500/5/589.

Almutahar, H. (2014). Perilaku Sosial Kesehatan Ibu Hamil Dan Melahirkan (Studi di Kawasan Perbatasan Kecamatan Seluas Kabupaten Bengkayang Propinsi Kalimanatan Barat). Sosiohumaniora, Volume 16 (3): 252 - 256

Ayaz, S. and Efe, Y.S. (2008). Potentially harmful traditional practices during pregnancy and postpartum. The European Journal of 
Contraception \& Reproductive Health Care, 13

(3), 282-288, DOI: $10.1080 / 13625180802049427$

Aziato, L., Odai, N.A,P, and Omenyo, N.C. (2016). Religious beliefs and practices in pregnancy and labour: an inductive qualitative study among post-partum women in Ghana. BMC Pregnancy and Childbirth, 16 (138), DOI 10.1186/s12884016-0920-1

Phipps, B. and Beech, L.B. (2004). Normal Birth: Women Stories. In: Downe, S (ed.), Normal Childbirth Evidence and Debate (pp. 59-70) Churchill livingstone: London.

Blackshaw, T. (2006). Fathers and Chidbirth.In: Squire C (ed.) The Social Context of Birth (pp. 211-232). Radcliffe Medical Press Ltd: Abingdon.

Choguya, N.Z. (2014). Traditional Birth Attendants and Policy Ambivalence in Zimbabwe. Journal of Anthropology . Article ID 750240, 9 pages http:// dx.doi.org/10.1155/2014/750240

Choudhury, N.C., Moran, C.A., Alam, A.M., Ahsan, Z.K., Rashid, F.S. and Streatfield, K.P. (2012). Beliefs and practices during pregnancy and childbirth in urban slums of Dhaka, Bangladesh. BMC Public Health.http://www.biomedcentral.com/14712458/12/791

Cooper, S. (2005). A Rite of Involvement?: Men's transition to fatherhood. Durham Anthropology Journal Volume 13(2) ISSN 1742-2930

Davis-Floyd, R (1992) Birth as an American Rite of Passage. Berkeley, Calif: University of California Press.

Ganapathy, T. (2016). Couvade syndrome among 1st time expectant fathers. Muller Journal of Medical Science and Research, 5(1), 43-47.

Gebuza, G., Kaźmierczak, M., Mieczkowska, E. and Banaszkiewicz, M. (2016). Adequacy Of Social Support And Satisfaction With Life During Childbirth. Polish Annals of Medicine, 23(1),135140.

Glazier, R., Elgar, F. and Holzapfel, S. (2004). Stress, Social Support, And Emotional Distress In A Community Sample Of Pregnant Women. Journal of Psychosomatic Obstetrics \& Gynecology. 25 (1), 247-255.

Graft, A.A. (2014). Food Beliefs and Practices During Pregnancy in Ghana:Implications for Maternal Health Interventions. Health Care for Women International, 35(7), 954-972.

Helman, G.C. (2002). Culture, Health and Illness. London: Arnold Publisher.

Higginbottom, M.A.G., Vallianatos, H., Joan Forgeron, J., Gibbons, D., Mamede, F. and Barolia, R.
(2014). Food Choices And Practices During Pregnancy Of Immigrant Women With HighRisk Pregnancies In Canada: A Pilot Study. BMC Pregnancy and Childbirth.http://www. biomedcentral.com/1471-2393/14/370

Hillier, D. (2003). Childbirth in the Global Village Implication for midwifery education and practice. London: Routledge.

Hindaryatiningsih, N. (2016). Model Proses Pewarisan Nilai-Nilai Budaya Lokal Dalam Tradisi Masyarakat Buton. Sosiohumaniora, Volume 18 (2): $100-107$

Mander, R. (2001). Supportive Care and Midwifery. London: Blackwell Science

McCourt, C. (2006). Social Support and Childbirth. In: Squire C (ed.) The Social Context of Birth (pp. 187-2009). Radcliffe Medical Press Ltd: Abingdon.

M'soka, N.C., Mabuza L.H. and Pretorius, D. (2010). Cultural And Health Beliefs Of Pregnant Women In Zambia Regarding Pregnancy And Child Birth. Curationis 38(1), Art.\#1232,7 pages. http:// dx.doi.org/10.4102/ curationis.v38i1.1232

Maharlouei, N. (2016). The Importance of Social Support During Pregnancy. Women's Health Bull, 3(1): e34991. doi: 10.17795/whb-34991

Naidu, M. and Koleki, N.K. (2013). Indigenous Mothers: An Ethnographic Study of Using the Environment during Pregnancy. Ethno Med, 7(2), 127-135

O’Neil, D. (2006). Processes of Change. http:// www. anthro.palomar.edu

Otoo, P., Habib, H. and Ankomah, A. (2015). Food Prohibitions and Other Traditional Practices in Pregnancy: A Qualitative Study in Western Region of Ghana. Advances in Reproductive Sciences, 3(1) 4149. http://dx.doi.org/10.4236/ arsci.2015.33005

Rowan, C. (2006). Maternal infant Attachment. In: Squire, C (eds) The Social Context of Birth (pp: 153-171). Radcliffe Medical Press Ltd: Abingdon

Thomas, C.J., Letourneau, N.N., Campbell, T. and Giesbrecht, F,G. (2015). Maternal social support during pregnancy supports postnatal maternal caregiving via reductions in prenatal depression. Paper presented at Alberta Children's Hospital Research Symposium, Calgary, April.

Van Gennep, A. (2004). The Rites of Passage. London: Routledge.

Winson,N., (2006). Transition To Motherhood. In: Squire, C (eds) The Social Context of Birth (pp: 137-151). Radcliffe Medical Press Ltd: Abingdon 